\title{
Lung Volume Reduction with Vapor Ablation in the Presence of Incomplete Fissures: 12-Month Results from the STEP-UP Randomized Controlled Study
}

\author{
Daniela Gompelmann ${ }^{\mathrm{a}, \mathrm{b}}$ Ralf Eberhardt ${ }^{\mathrm{a}, \mathrm{b}}$ Maren Schuhmann ${ }^{\mathrm{a}}$ \\ Arschang Valipour $^{c}$ Pallav L. Shah ${ }^{d}$ Felix J.F. Herth ${ }^{a, b}$ \\ Konstantina Kontogianni ${ }^{a}$ \\ a Department of Pneumology and Critical Care Medicine, Thoraxklinik at University of Heidelberg, and \\ ${ }^{b}$ Translational Lung Research Center Heidelberg (TLRCH), German Lung Research Foundation (DZL), Heidelberg, \\ Germany; ${ }^{\circ}$ Department of Respiratory and Critical Care Medicine, Ludwig-Boltzmann-Institute for COPD and \\ Respiratory Epidemiology, Otto-Wagner-Hospital, Vienna, Austria; ${ }^{\mathrm{d}}$ The National Institute for Health Research \\ Respiratory Biomedical Research Unit, Royal Brompton and Harefield NHS Foundation Trust and Imperial College, \\ London, UK
}

\section{Keywords}

Endoscopic lung volume reduction · Emphysema · Vapor ablation

\footnotetext{
Abstract

Background: Emphysema patients with collateral ventilation (CV) will not benefit from valve therapy, the most common endoscopic lung volume reduction procedure. A recent randomized controlled trial (STEP-UP) of the alternative bronchoscopic thermal vapor ablation (BTVA) included patients with $(\mathrm{CV}+)$ and without interlobar CV (CV-). Objectives: This analysis evaluated the efficacy and safety of the $\mathrm{CV}+$ population following BTVA. Method: A post hoc fissure analysis of the baseline computed tomography of all treatment and control patients was performed with the VIDA Diagnostics Apollo software. A patient was considered to be $\mathrm{CV}+$ if either of the treated upper lobes was adjacent to a fissure that was $<90 \%$ complete. The primary endpoints,
}

forced expiratory volume in $1 \mathrm{~s}\left(\mathrm{FEV}_{1}\right)$ and St. George's Respiratory Questionnaire (SGRQ-C), were calculated for these $\mathrm{CV}+$ patients following BTVA and safety results summarized. Results: $78 \%$ (35/45) of the patients in the treatment arm and $79 \%(19 / 24)$ of the patients in the control arm were found to be $\mathrm{CV}+$. At 12 months, the $\mathrm{FEV}_{1}$ improvement of the treatment arm was $9.2 \%$, as compared with a decrease of $5.4 \%$ in the control group, resulting in a mean betweengroup difference of $14.6 \%(p=0.0137)$. The improvement in SGRQ-C of the treatment arm as compared to the control arm was 8.4 points $(p=0.0712)$. An increase in respiratory related serious adverse events was observed immediately following treatment, but most resolved with routine care. Conclusion: BTVA can achieve safe and clinically meaningful improvement in pulmonary function and quality of life in patients with CV. These randomized controlled trial subgroup results offer proof of a viable solution for $\mathrm{CV}+$ patients.

(c) 2016 S. Karger AG, Basel

\section{KARGER}

E-Mail karger@karger.com

www.karger.com/res
2016 S. Karger AG, Basel

0025-7931/16/0926-0397\$39.50/0
Dr. med. Daniela Gompelmann

Department of Pneumology and Critical Care Medicine

Thoraxklinik at University of Heidelberg, Röntgenstrasse 1

DE-69126 Heidelberg (Germany)

E-Mail daniela.gompelmann@med.uni-heidelberg.de 


\section{Introduction}

Lung volume reduction surgery (LVRS) minimizes hyperinflation and has been demonstrated to improve quality of life and lung function in patients with severe emphysema [1]. However, as LVRS is associated with significant morbidity and mortality, endoscopic approaches to lung volume reduction have been developed and studied. The most widespread of these is the endoscopic valve therapy that shows promising results, but only in patients without interlobar collateral ventilation (CV) [2-4]. Thereby, valves are placed in all segments of an emphysematous lobe (lobar exclusion) and are designed to allow air to escape from the treated lobe but prevent air from entering the treated lobe during inspiration. When successful, the lung parenchyma distal to the obstruction collapses and becomes atelectatic, creating lung volume reduction $[2,3]$. However, many patients have lungs with $\mathrm{CV}$ between lobes, which prevents the intended complete occlusion effect through maintenance of airflow via the collateral channels. Therefore, these patients with interlobar $\mathrm{CV}(\mathrm{CV}+)$ will not benefit from endoscopic valve therapy and have limited options for an effective endoscopic lung volume reduction (ELVR).

Bronchoscopic thermal vapor ablation (BTVA) is a unique approach to ELVR that is capable of inducing volume reduction at the segmental level $[5,6]$. Most patients have highly diseased and relatively healthy segments within the same lobe [7]. Vapor is capable of reducing only the highly diseased segments while preserving the remaining segments because lobar exclusion is not necessary.

Interlobar fissure completeness is a surrogate for low $\mathrm{CV}$ and can be evaluated using the multidetector computed tomography scan (MDCT). This parameter has never been a prerequisite for vapor ablation, and patients with incomplete fissures and CV have always been included in previous studies $[8,9]$. One retrospective study in a small patient cohort has already demonstrated that lobar fissure integrity (FI) has no or minimal influence on BTVA-induced volume reduction [10].

The recent Sequential Staged Treatment of Emphysema with Upper Lobe Predominance (STEP-UP) trial was the first multinational, multicenter, randomized controlled study to investigate the segmental approach of BTVA [5]. In this study, we present a post hoc analysis of STEP-UP treatment and control patients with incomplete fissures to evaluate the clinical outcomes of this $\mathrm{CV}+$ subgroup only. Since these patients have few other safe and effective ELVR options, it is important to understand the outcomes in this specific cohort.

\section{Material and Methods}

\section{Study Design and Participants}

Full details of the STEP-UP study design and results have been previously reported $[5,11,12]$. In brief, adult patients with upper lobe-predominant heterogeneous emphysema were enrolled from 13 multinational hospital sites. Selection criteria were similar to other ELVR randomized controlled trials and the National Emphysema Treatment Trial (NETT) $[1,13,14]$. The study was limited to patients with evidence of upper lobe-predominant heterogeneous emphysema ( $>15 \%$ difference in lung density between targeted upper lobe segment and its respective lower lobe) [5-7]. FI was not an inclusion or exclusion criterion. Patients who met all study criteria were randomly assigned $2: 1$ and received therapy $(n=45)$ with InterVapor ${ }^{\circledR}$ (Uptake Medical, Seattle, WA, USA) or medical management $(n=24)$. Patients in the treatment arm received treatment of one segment in one upper lobe followed by treatment of one or two segments in the other upper lobe 90 days later in addition to standard medical management as previously published. Vapor ablation treatment induces lung volume reduction by the bronchoscopic delivery of heated water vapor through a catheter. An occlusion balloon at the tip of the catheter is inflated to occlude the target region and 3-10 s of water vapor is delivered depending on the mass and volume of the segment to be treated. Patients in the control group received standard medical management consistent with the Global Initiative for Chronic Obstructive Lung Disease (GOLD) guidelines [15]. In both study groups, the patients were followed for 12 months. All enrolled patients provided a completed written informed consent form that was reviewed and approved by the Institutional Review Board or Ethics Committee of all participating hospital sites. All participating sites provided ethics consent and protocol approval. Primary endpoints were forced expiratory volume in $1 \mathrm{~s}\left(\mathrm{FEV}_{1}\right)$ and healthrelated quality of life assessed using the St. George's Respiratory Questionnaire (SGRQ-C) at 12 months. Safety was evaluated by comparing rates of serious adverse events (SAEs), including exacerbation, pneumonia, pneumothorax, hemoptysis, and death, between trial groups.

\section{Evaluation of Fissure Integrity}

A priori analysis of baseline MDCT scans was performed to calculate segment mass, volume, and density for dosing and segment selection purposes. An additional post hoc analysis of FI assessment was performed on the same baseline MDCT scans for each treatment and control patient. FI was calculated with the same VIDA Diagnostics Apollo version 2.1 software by 2 VIDA CT core lab analysts. Each analyst independently performed an analysis and the average score was computed and used for this study. Since only upper lobes were treated, only the fissures adjacent to the upper lobes were considered. These were the left oblique fissure (LOF) for the left and combination of right oblique fissure and horizontal fissure (ROHF) for the right. FI $\geq 90 \%$ complete has been previously shown in multiple studies to predict the response outcome in valve procedures, as an incomplete interlobar fissure is a surrogate for CV between lobes [2, 3 $13,16-19]$. In this study, a threshold of $<90 \%$ complete was used to define incomplete fissures, and these lungs were assumed to have $\mathrm{CV}$. 
Statistical Analysis

In this study, a subset of the original STEP-UP trial is considered, i.e., only treatment and control patients with incomplete fissures in either lung (FI $<90 \%$ for LOF or ROHF). The same efficacy primary and secondary endpoints of the original STEP-UP trial for the treatment group are compared against the control group. A comparison of SAEs is also done. Between-group statistical comparisons for the post hoc subset analysis was performed with the same method as the original STEP-UP report. Analysis was done on the intention-to-treat population at 12 months. The Hochberg method was used to compensate for multiple comparisons resulting from 2 endpoints. If both primary endpoints $\left(\mathrm{FEV}_{1}\right.$ and SGRQ-C) reached clinical significance at the 0.05 level, or if either 1 of the 2 endpoints reached clinical significance at the 0.025 level, it is considered a positive result. We computed $p$ values for discrete variables using Fisher's exact test and $p$ values for continuous variables using the two-sample $t$ test.

\section{Results}

In the treatment arm, $78 \%(35 / 45)$ of the patients were found to have 1 or more incomplete fissures adjacent to a treated lobe and were considered to be $\mathrm{CV}+$. The $\mathrm{LOF}$ was incomplete in $38 \%$ and the ROHF in $76 \%$. In the control arm, 79\% (19/24) of the patients had 1 or more incomplete fissures. In this group, the LOF was incomplete in $46 \%$ and the ROHF in $71 \%$ of the patients.

In patients with incomplete fissures, the treated patients demonstrated a significant $(p \leq 0.025)$ improvement - compared to standard care - for at least 1 of the primary efficacy endpoints $\mathrm{FEV}_{1}$ and SGRQ-C at 12 months, meeting the statistical criteria of the original study design. The mean difference in $\mathrm{FEV}_{1}$ between trial groups at 12 months was $14.6 \%$ (95\% CI $2.5-26.7 ; p=$ 0.0137; Fig. 1). The mean difference in SGRQ-C between trial groups at 12 months was -8.4 points ( $95 \%$ CI 1.1 to $-17.9 ; p=0.0712$; Fig. 2 ). Over the 1-year period, the largest improvement of $\mathrm{FEV}_{1}$ and SGRQ-C was observed at 12 months after treatment. Table 1 shows the results for the primary efficacy endpoints and Table 2 for the secondary efficacy endpoints. A binary responder analysis was done to indicate the minimal clinically important difference in pulmonary function $\left(\mathrm{FEV}_{1} \geq 12 \%\right)$ or quality of life (SGRQ-C $\leq-8$ points). The proportion of this patient subgroup achieving a minimal clinically important difference from baseline in either endpoint at 12 months was $62 \%$.

SAEs were monitored in both trial groups as the primary safety endpoint. In this subgroup of $\mathrm{CV}+$ patients, exacerbations and pneumonia 90 days posttreatment 1 and 2 (180 days posttreatment 1$)$ were more common in

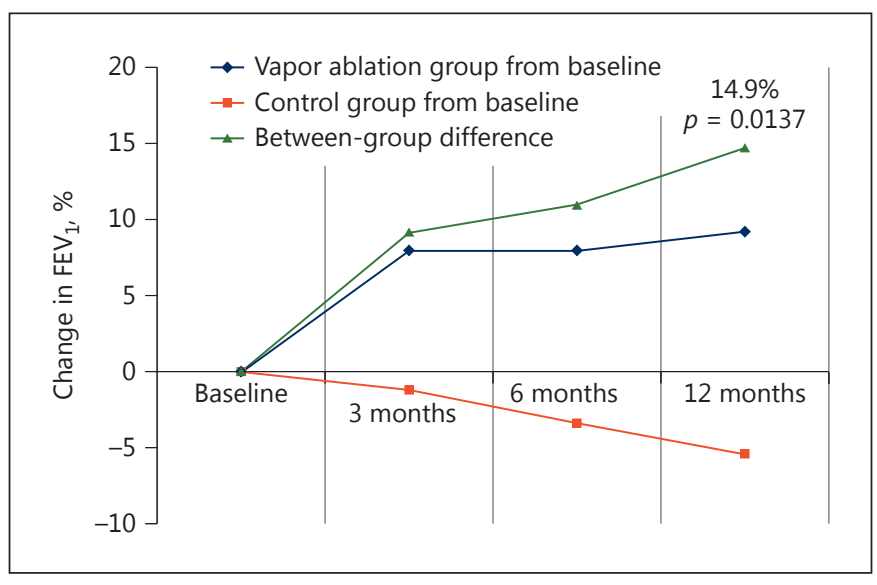

Fig. 1. Changes in $\mathrm{FEV}_{1}$ over 12 months after vapor ablation compared to the control arm with in between-group difference.

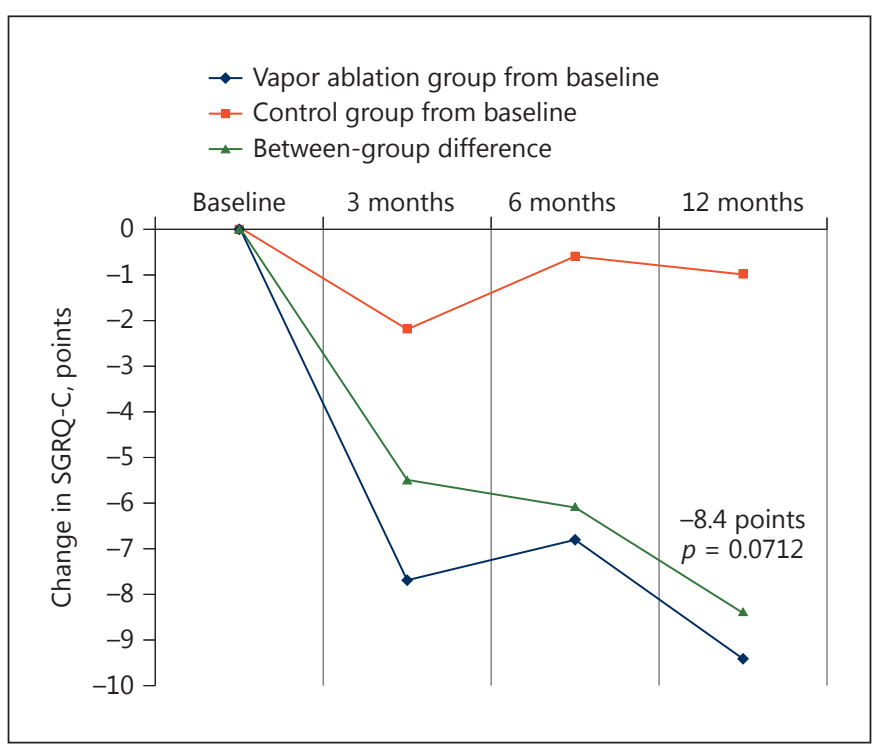

Fig. 2. Changes in SGRQ-C over 12 months after vapor ablation compared to the control arm with in between-group difference.

the treatment group than in the control group and most resolved with standard of care. In the treatment subgroup, $8(23 \%)$ patients had pneumonia or pneumonitis and 3 (9\%) had COPD exacerbations requiring hospital admission within the 180-day timeframe after treatment 1 . No incidences of hemoptysis or pneumothorax requiring intervention were observed.

Overall, the procedure was well tolerated with routine hospital stay and recovery without intervention for all SAEs, with the exception of $2(6 \%)$ patients. One (3\%) patient died 84 days after treatment from complications 
Table 1. Results for primary efficacy endpoints for patients with incomplete fissures

\begin{tabular}{|c|c|c|c|c|}
\hline & $\begin{array}{l}\text { Bronchoscopic vapor } \\
\text { ablation group }\end{array}$ & $\begin{array}{l}\text { Control } \\
\text { group }\end{array}$ & $\begin{array}{l}\text { Difference between } \\
\text { groups }(95 \% \mathrm{CI})\end{array}$ & $p$ value \\
\hline $\begin{array}{l}\text { Patients with incomplete fissures, } n \\
\Delta \mathrm{FEV}_{1}, \%\end{array}$ & 35 & 19 & & \\
\hline 3 months & 7.9 & -1.2 & $9.1(0.1$ to 18.1$)$ & 0.0056 \\
\hline 6 months & 7.6 & -3.4 & $10.9(3.6$ to 18.4 & 0.0024 \\
\hline 12 months & 9.2 & -5.4 & $14.6(3.1$ to 26.7$)$ & 0.0137 \\
\hline \multicolumn{5}{|l|}{$\Delta$ SGRQ-C (points) } \\
\hline 3 months & -7.7 & -2.2 & $-5.5(0.5$ to -11.5$)$ & 0.0697 \\
\hline 6 months & -6.8 & -0.6 & $-6.1(1.3$ to -13.7$)$ & 0.1089 \\
\hline 12 months & -9.4 & -1.0 & $-8.4(0.7$ to -17.5$)$ & 0.0712 \\
\hline
\end{tabular}

$\mathrm{FEV}_{1}$, forced expiratory volume in $1 \mathrm{~s}$. SGRQ-C, St George's Respiratory Questionnaire. Data available for all patients at 12 months except 1 treatment patient that died and 1 control patient that withdrew.

Table 2. Results for secondary efficacy endpoints at 12 months for patients with incomplete fissures

\begin{tabular}{|c|c|c|c|c|}
\hline & $\begin{array}{l}\text { Bronchoscopic vapor } \\
\text { ablation group }\end{array}$ & $\begin{array}{l}\text { Control } \\
\text { group }\end{array}$ & $\begin{array}{l}\text { Difference between } \\
\text { groups }(95 \% \mathrm{CI})\end{array}$ & $p$ value \\
\hline $\begin{array}{l}\text { Patients with incomplete fissures, } n \\
\Delta \mathrm{FEV}_{1}, \mathrm{~mL}\end{array}$ & 35 & 19 & & \\
\hline 3 months & 64.4 & -22.8 & $87.2(7.5$ to 166.9$)$ & 0.0326 \\
\hline 6 months & 58.1 & -31.1 & $89.2(20.4$ to 158.0$)$ & 0.0122 \\
\hline 12 months & 65.0 & -46.7 & 111.7 (18.5 to 204.9$)$ & 0.0198 \\
\hline \multicolumn{5}{|l|}{$\Delta \mathrm{FVC}, \mathrm{mL}$} \\
\hline 3 months & 87.6 & -96.1 & $183.8(-16.1$ to 383.5$)$ & 0.0706 \\
\hline 6 months & 97.1 & -88.3 & $185.4(-24.0$ to 394.8$)$ & 0.0813 \\
\hline 12 months & 98.2 & -96.1 & $194.3(-50.4$ to 439.0$)$ & 0.1170 \\
\hline \multicolumn{5}{|l|}{$\Delta \mathrm{RV}, \mathrm{mL}$} \\
\hline 3 months & -52.9 & -27.8 & $-25.2(-383.3$ to 333.1$)$ & 0.8884 \\
\hline 6 months & -261.3 & 44.4 & $-305.7(-608.1$ to -3.3$)$ & 0.0477 \\
\hline 12 months & -108.8 & 111.1 & $-214.1(-559.3$ to 119.5$)$ & 0.1991 \\
\hline \multicolumn{5}{|l|}{$\Delta \mathrm{FRC}, \mathrm{mL}$} \\
\hline 3 months & -64.7 & -11.1 & $-53.6(-443.9$ to 336.7$)$ & 0.7838 \\
\hline 6 months & -119.4 & 16.7 & $-136.0(-459.8$ to 187.6$)$ & 0.4021 \\
\hline 12 months & -126.5 & 122.2 & $-248.7(-581.7$ to 84.3$)$ & 0.1399 \\
\hline \multicolumn{5}{|l|}{$\Delta 6 \mathrm{MWT}, \mathrm{m}$} \\
\hline 3 months & 12.1 & -19.9 & $32.0(6.6$ to 70.6$)$ & 0.1021 \\
\hline 6 months & 13.7 & -10.6 & $24.3(-10.9$ to 59.5$)$ & 0.1718 \\
\hline 12 months & 6.2 & -4.8 & $10.8(-24.9$ to 46.9$)$ & 0.5389 \\
\hline
\end{tabular}

$\mathrm{FEV}_{1}$, forced expiratory volume in $1 \mathrm{~s}$. FVC, forced vital capacity; RV, residual volume; FRC, functional residual capacity (thoracic gas volume); 6MWT, 6-min walk test. Data available for all patients at 12 months except for 1 treatment patient that died and 1 control patient that withdrew.

related to COPD exacerbation. This death was reviewed by the data and safety monitoring board and was judged to be possibly related to treatment. One patient had a pneumonia requiring an ICU stay; however, the patient did not necessitate invasive mechanical ventilation, and made a full recovery. There were no unanticipated SAEs related to vapor ablation during the course of the study.

There were no SAEs observed in the treatment subgroup in the 181-365-day observation period. There were 3 (16\%) patients with respiratory SAEs in the control 
Table 3. SAEs and hospital admissions

\begin{tabular}{|c|c|c|c|c|}
\hline & \multicolumn{2}{|c|}{ Treatment group $(n=35)$} & \multicolumn{2}{|c|}{ Control group $(n=19)$} \\
\hline & $\begin{array}{l}0-180 \text { days after } \\
\text { treatment }^{1}\end{array}$ & $\begin{array}{l}181-365 \text { days after } \\
\text { treatment }^{1}\end{array}$ & $\begin{array}{l}0-180 \text { days after } \\
\text { randomization }\end{array}$ & $\begin{array}{l}181-365 \text { days after } \\
\text { randomization }\end{array}$ \\
\hline COPD exacerbation & $3(9)$ & 0 & $1(5)$ & $2(11)$ \\
\hline Pneumonia or pneumonitis & $8(23)$ & 0 & $1(5)$ & $1(5)$ \\
\hline Pneumothorax & $1^{2}(3)$ & 0 & 0 & 0 \\
\hline Hemoptysis & 0 & 0 & 0 & 0 \\
\hline Death & $1(3)$ & 0 & 0 & 0 \\
\hline Any respiratory SAE & $9(26)$ & 0 & $2(11)$ & $3(16)$ \\
\hline
\end{tabular}

Data are $n(\%) .{ }^{1}$ Days after treatment session $1 .{ }^{2}$ Incidental finding at follow-up, resolved without intervention.

group in the 181-365-day observation period, suggesting an improvement in complication rate over baseline following vapor ablation. The occurrence of these respiratory SAEs is reported in Table 3.

\section{Discussion}

It is well established that ELVR with occlusion by valves do not demonstrate significant or minimal clinically important improvement in pulmonary function or quality of life in a population of patients with incomplete fissures or interlobar CV [2, 3, 13, 16-19]. For this reason, valves are not used in clinical practice in lungs with incomplete fissures or CV. Therefore, there is a large portion of the severe emphysema population that is unserved.

For these $\mathrm{CV}+$ patients, endoscopic coil therapy, polymeric lung volume reduction, and BTVA are examined $[10,20,21]$. Endoscopic coil therapy improves exercise capacity in patients with severe lung hyperinflation but of uncertain clinical importance [14]. To date, there are only few predictors for successful coil treatment leading to insufficient patient selection and requiring further investigation. For the polymeric lung volume reduction, only few data that demonstrate promising efficacy results are available, as this technique has not been available on the market since 2013 [22]. Furthermore, there are no randomized controlled trial data demonstrating clinically meaningful improvement following coil therapy or polymeric lung volume reduction in this $\mathrm{CV}+$ patient population.

In the multinational, multicenter randomized controlled STEP-UP trial of vapor ablation, fissure incompleteness or $\mathrm{CV}+$ status was not a contraindication. In this post hoc analysis, it was found that $78 \%$ of the treated patients had incomplete fissures ( $<90 \%$ complete) adjacent to 1 or both of the treated lobes. This high percentage of patients with interlobar CV is similar compared to the results of other investigations [4].

The results of this study of the STEP-UP subgroup with incomplete fissures showed that significant and clinically important difference improvement in $\mathrm{FEV}_{1}$ and quality of life occurs after vapor ablation despite the presence of CV. Compared with standard care, the primary endpoint of $\mathrm{FEV}_{1}$ and the SGRQ-C total score were improved at 12 months in this subgroup ( $p=0.0137$ and 0.0712 ) and considered as statistically significant positive result using the Hochberg method. These results were similar to the efficacy data of the total patient cohort including CV- patients [12]. Notwithstanding the FI, the mean difference in $\mathrm{FEV}_{1}$ between all treated patients and all patients of the control group was $12.8 \%$, and in SGRQ$\mathrm{C}$, it was -12.1 points at 12 months (both $p<0.05$ ).

The STEP-UP CV+ study results are consistent with data of another retrospective analysis of a multicenter single arm trial, where 44 patients with upper lobe predominant emphysema were treated unilaterally by BTVA [10]. In that patient cohort, $86 \%$ of the patients had incompleteness in the relevant fissure. There was no or only minimal relationship between the FI and lung function parameters, 6-min walk distance (6-MWD) and SGRQ following BTVA. In this first trial, a vapor ablation was performed on a lobar level in comparison to the stepwise segmental approach in the current analysis. The aim of the subsequent vapor ablation on a sublobar basis is to target only the most diseased segments while the healthier segments should be preserved. Furthermore, the stepwise strategy aims to improve the risk-benefit profile. 
Thus, the current analysis demonstrated that this new segmental vapor ablation can benefit $\mathrm{CV}+$ patients with upper lobe predominant emphysema.

SAEs were monitored in both CV+ control and treatment groups as the primary safety endpoint. An increase in the occurrence of SAEs in the period immediately following treatment is expected and is common in other published ELVR randomized controlled trials. All adverse events that occurred in this subgroup were managed with standard medical care with the exception of 1 patient that died and another that required a nonmechanical ventilation ICU stay for pneumonia. No pneumothorax requiring intervention or hemoptysis was observed.

The main limitation of this study is that it was not part of the a priori clinical investigation plan. However, the subgroup studied is a large majority of the full cohort and statistical significance remains strong. Other limitations are the same as the original STEP-UP study. While the investigators, patients, and sponsor were blinded to compiled summary statistics, a full double-blinded study was not feasible as the treatment effect is usually apparent on imaging and it would require a sham procedure of the control group, which was not possible due to ethical concerns.

Emphysema has no known cure and patients progressively lose pulmonary function over time. The strategy of reducing the most diseased segments with vapor ablation and preserving less diseased segments, safely and positively affects lung function and quality of life even in CV+ patients. Vapor ablation is unique in its ability to address this large population of $\mathrm{CV}+$ patients as well as the potential to deliver additional treatment over time as the disease inevitably progresses.

\section{Acknowledgements}

The STEP-UP study was funded by Uptake Medical. The investigators' host institutions have received financial and research support from Uptake Medical for the purpose of the STEP-UP study, but the investigators do not own any stock in the company.

\section{References}

-1 Fishman A, Martinez F, Naunheim K, Piantadosi S, Wise R, Ries A, Weinmann G, Wood DE; National Emphysema Treatment Trial Research Group: A randomized trial comparing lung-volume-reduction surgery with medical therapy for severe emphysema. N Engl J Med 2003;348:2059-2073.

-2 Davey C, Zoumot Z, Jordan S, McNulty WH, Carr DH, Hind MD, Hansell DM, Rubens MB, Banya W, Polkey MI, Shah PL, Hopkinson NS: Bronchoscopic lung volume reduction with endobronchial valves for patients with heterogeneous emphysema and intact interlobar fissures (the BeLieVeR-HIFi study): a randomised controlled trial. Lancet 2015;386:1066-1073.

>3 Klooster K, Ten Hacken NHT, Hartman JE, Kerstjens HAM, van Rikxoort EM, Slebos DJ: Endobronchial valves for emphysema without interlobar collateral ventilation. $\mathrm{N}$ Engl J Med 2015;373:2325-2335.

$\checkmark 4$ Koster TD, Slebos D: The fissure: interlobar collateral ventilation and implications for endoscopic therapy in emphysema. Int J Chron Obstruct Pulmon Dis 2016;11:765-773.

5 Herth FJF, Valipour A, Shah PL, Eberhardt R, Grah C, Egan J, Ficker JH, Wagner M, Witt C, Liebers U, Hopkins P, Gesierich W, Phillips M, Stanzel F, McNulty WH, Petermann C, Snell G, Gompelmann D: Segmental volume reduction using thermal vapour ablation in patients with severe emphysema: 6-month results of the multicentre, parallel-group, open- label, randomised controlled STEP-UP trial. Lancet Respir Med 2016;2600:1-9.

-6 Bandyopadhyay S, Henne E, Gupta A, Barry R, Snell G, Strange C, Herth FJ: Segmental approach to lung volume reduction therapy for emphysema patients. Respiration 2014;89: 76-81.

7 Valipour A, Shah L, Gesierich W, Eberhardt R, Snell G, Strange C, Barry R, Gupta A, Henne E, Bandyopadhyay S, Raffy P, Yin Y, Tschirren J, Herth FJ: Patterns of emphysema heterogeneity. Respiration 2015;90:402-411.

>8 Snell GI, Hopkins P, Westall G, Holsworth L, Carle A, Williams TJ: A feasibility and safety study of bronchoscopic thermal vapor ablation: a novel emphysema therapy. Ann Thorac Surg 2009;88:1993-1998.

$\checkmark 9$ Herth FJF, Ernst A, Baker KM, Egan JJ, Gotfried MH, Hopkins P, Stanzel F, Valipour A, Wagner M, Witt C, Kesten S, Snell G: Characterization of outcomes 1 year after endoscopic thermal vapor ablation for patients with heterogeneous emphysema. Int J Chron Obstruct Pulmon Dis 2012;7:397-405.

10 Gompelmann D, Heussel CP, Eberhardt R, Snell G, Hopkins P, Baker K, Witt C, Valipour A, Wagner M, Stanzel F, Egan J, Ernst A, Kesten S, Herth FJ: Efficacy of bronchoscopic thermal vapor ablation and lobar fissure completeness in patients with heterogeneous emphysema. Respiration 2012;83:400-406.

$>11$ Valipour A, Herth FJF, Eberhardt R, Shah PL, Gupta A, Barry R, Henne E, Bandyopad- hyay S, Snell G: Design of the randomized, controlled sequential staged treatment of emphysema with upper lobe predominance (STEP-UP) study. BMC Pulm Med 2014;14: 190

12 Shah PL, Gompelmann D, Valipour A, McNulty WH, Eberhardt R, Grah C, Egan J, Ficker JH, Wagner M, Witt C, Liebers U, Hopkins P, Gesierich W, Phillips M, Stanzel F, Petermann C, Strange C, Snell G, Herth FJ: Thermal vapour ablation to reduce segmental volume in patients with severe emphysema: STEP-UP 12 month results. Lancet Respir Med 2016;4:e44-e45.

$>13$ Herth FJF, Noppen M, Valipour A, Leroy S, Vergnon JM, Ficker JH, Egan JJ, Gasparini S, Agusti C, Holmes-Higgin D, Ernst A; International VENT Study Group: Efficacy predictors of lung volume reduction with Zephyr valves in a European cohort. Eur Respir J 2012;39:1334-1342.

14 Sciurba FC, Criner GJ, Strange C, Shah PL, Michaud G, Connolly TA, Deslée G, Tillis WP, Delage A, Marquette CH, Krishna G, Kalhan R, Ferguson JS, Jantz M, Maldonado F, McKenna R, Majid A, Rai N, Gay S, Dransfield MT, Angel L, Maxfiels R, Herth FJ, Wahidi MM, Mehta A, Slebos DJ; RENEW Study Research Group: Effect of endobronchial coils vs. usual care on exercise tolerance in patients with severe emphysema: The RENEW Randomized Clinical Trial. JAMA 2016;315: 2178-2189. 
15 Vestbo J, Hurd SS, Agustí AG, Jones PW, Vogelmeier C, Anzueto A, Barnes PJ, Fabbri LM, Martinez FJ, Nishimura M, Stockley RA, Sin DD, Rodriguez-Roisin R: Global strategy for the diagnosis, management, and prevention of chronic obstructive pulmonary disease: GOLD executive summary. Am J Respir Crit Care Med 2013;187:347-365.

16 Sciurba FC, Ernst A, Herth FJF, Strange C, Criner GJ, Marquette CH, Kovitz KL, Chiacchierini RP, Goldin J, McLennan G; VENT Study Research Group: A randomized study of endobronchial valves for advanced emphysema. N Engl J Med 2010;363:1233-1244.

17 Schuhmann M, Raffy P, Yin Y, Gompelmann D, Oguz I, Eberhardt R, Hornberg D, Heussel CP, Wood S, Herth FJ l: Computed tomography predictors of response to endobronchial valve lung reduction treatment: comparison with Chartis. Am J Respir Crit Care Med 2015;191:767-774.
18 Gompelmann D, Eberhardt R, Slebos DJ, Brown MS, Abtin F, Kim HJ, Holmes-Higgin D, Radhakrishnan S, Herth FJF, Goldin J: Diagnostic performance comparison of the Chartis System and high-resolution computerized tomography fissure analysis for planning endoscopic lung volume reduction. Respirology 2014;19:524-530.

19 Herth FJ, Eberhardt R, Gompelmann D, Ficker JH, Wagner M, Ek L, Schmidt B, Slebos DJ: Radiological and clinical outcomes of using Chartis ${ }^{\mathrm{TM}}$ to plan endobronchial valve treatment. Eur Respir J 2012;39:1334-1342.

20 Kontogianni K, Gerovasili V, Gompelmann D, Schuhmann M, Heussel CP, Herth JF, Eberhardt R: Effectiveness of endobronchial coil treatment for lung volume reduction in patients with severe heterogeneous emphysema and bilateral incomplete fissures: a six-month follow-up. Respiration 2014;88:52-60.
1 Magnussen H, Kramer MR, Kirsten AM, Marquette C, Valipour A, Stanzel F, Bonnet R, Behr J, Fruchter O, Refaely Y, Eberhardt R, Herth FJ: Effect of fissure integrity on lung volume reduction using a polymer sealant in advanced emphysema. Thorax 2012;67:302308.

22 Come CE, Kramer MR, Dransfield MT, AbuHijleh M, Berkowitz D, Bezzi M, Bhatt SP, Boyd MB, Cases E, Chen AC, Cooper CB, Flandes J, Gildea T, Gotfried M, Hogarth DK, Kolandaivelu K, Leeds W, Liesching T, Marchetti N, Marquette C, Mularski RA, PintoPlata VM, Pritchett MA, Rafeq S, Rubio ER, Slebos DJ, Stratakos G, Sy A, Tsai LW, Wahidi M, Walsh J, Wells JM, Whitten PE, Yusen R, Zulueta JJ, Criner GJ, Washko GR: A randomized trial of lung sealant versus medical therapy for advanced emphysema. Eur Respir J 2015;46:651-662. 